\title{
Outsourcing: condition and perspectives of development of accounting services in Russia
}

\author{
Nadezhda Palesheva ${ }^{1 *}$, Nadezhda Zonova ${ }^{1}$, Svetlana Grin ${ }^{1}$ \\ ${ }^{1}$ Vyatka State University, Preobrazhenskaya St., 41, 610020 Kirov, Russia
}

\begin{abstract}
The article discusses the state of the market for outsourcing accounting services in the Russian Federation and its development trends, the forms of interaction between customers and outsourcers in the accounting and financial field. The purpose of the article is to analyze the content and main characteristics of outsourcing accounting services, features and ways of its further development in Russia in modern economic conditions. The study of the authors is based on an analysis of open sources of information: the company's websites, the Federal State Statistics Service, the Federal Tax Service of Russia, scientific publications. Particular attention is paid to the study of publications of Russian and foreign authors, the assessment of the size, conditions and prospects of development of the market for accounting services in Russia. In particular, the factors that affect the accounting outsourcing industry have been identified. The authors made conclusions about the emergence of new players in the market for accounting outsourcing services, their approaches to the provision of services, identified the main prospects for the development of accounting business through deeper use of modern information and communication technologies and integration.
\end{abstract}

\section{Introduction}

One of the important components of business development is the provision of highquality accounting services, which include the organization and maintenance of business and tax accounting on the enterprise, the provision of all types of reports, tax and financial advice. Their level is largely determined by the professionalism and competence of the accounting staff. This circumstance motivates the head of the company to make a choice: hire a fulltime accountant, use the services of a private accountant, or give preference to a company that provides accounting outsourcing services.

Overseas, accounting outsourcing is very popular because it expands opportunities for effective business. Its development is associated with globalization processes, the appearance of networked and cluster forms of business organization, global information systems and big data processing, as well as improved quality service. In Russia, outsourcing of accounting services is a young, fast-growing business, it has specific features that require consideration and in-depth study It should be noted that much attention is paid to the research

\footnotetext{
${ }^{*}$ Corresponding author: kafinanc@yandex.ru
} 
of the outsourcing market. However, the real situation in the market for accounting outsourcing raises a number of issues that require further consideration and in-depth study.

\section{Methods and Materials}

To give an objective assessment of the state of the accounting services market, analytical studies were conducted based on data from the Federal State Statistics Service, the Federal Tax Service of Russia, Russian and foreign analytical agencies, and IT companies. Identification of the main problems and ways to solve them in the field of outsourcing accounting services was made possible thanks to the interviewing and personal professional experience of the authors. The results of the monitoring of "accounting" services offers show that at present there is no common understanding of the functional content of the concept of "outsourced accounting services", which, in particular, is indicated by the huge gap in their price stated in various promotional offers. To clarify the content of the concept of outsourcing in the field of accounting, an analysis of the publications of the following foreign authors was carried out: Cui, Lan, Liu, Donghui [1], Wahby, Riad S., Ji, Ye; Blumberg, Andrew J. [2], Zekic, B.H., Lutilsky, I.D., Liovic D, [3] as well as the works of Russian scientists B.A. Anikin, Z.S. Ayvazyana, S.O. Kalenjyan, I.L. Rudoy and other researchers. $[6,13,16]$. Works of G.N. Gafurova, I.V Tikhonova ,. A.S. Kramskikh, I.V. Ovchinnikova, E.V. Ostanina., S.R. Simonyan, Yu.S. Lebedinskaya is devoted to the study of accounting outsourcing $[5,10,17]$.

Substantiation of the prospects for the development of accounting outsourcing in Russia was carried out according to the results of the collected analysis material, the sources for which were the authors' own observations and the results of research by Western and Russian scientists.

\section{Results}

At present time, players in the accounting outsourcing market are specialized outsourcing companies, audit firms, IT companies, freelancers, private experts and online services of financial companies. According to many analysts, the main share (over 50\%) in this segment is occupied by outsourcing companies. The most complete source of information on the market for accounting outsourcing is the Expert magazine ranking, which provides information on the largest companies in the industry. According to the rating agency Expert [11], the total revenue of the largest outsourcing providers for 2016 amounted to 7.8 billion and increased by $7 \%$ compared with previous periods. Outsourcing of comprehensive accounting and tax accounting prevails in the revenue structure (Fig. 1) 


\section{Revenue structure of the ranking participants at the end of 2016}
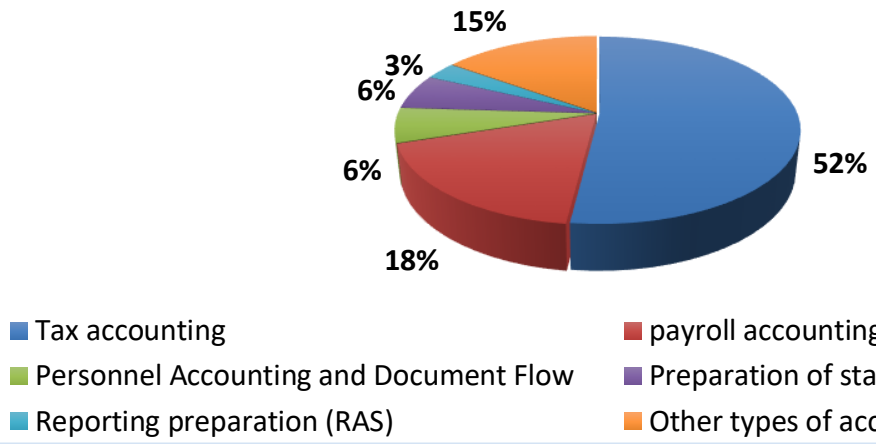

Fig. 1. Revenue structure of accounting outsourcing companies ranking participants.

According to the website www.business.ru, legal and financial services in the Russian Federation retain their popularity. If we refer to the official data on organizations whose main activity relates to activities in the field of law and accounting according to Russian Federal Statistic, there are 42353 of them, which is $0.92 \%$ of the total or $10.83 \%$ of the number of organizations related to this classification group for OKVED (professional, scientific and technical activities).

Of interest is the geographical concentration of organizations that provide accounting services by region and federal districts. Figure 2 shows the distribution of the number of organizations in the context of administrative and territorial divisions of the Russian Federation, whose main activity is the provision of accounting services, financial audits, tax advice.

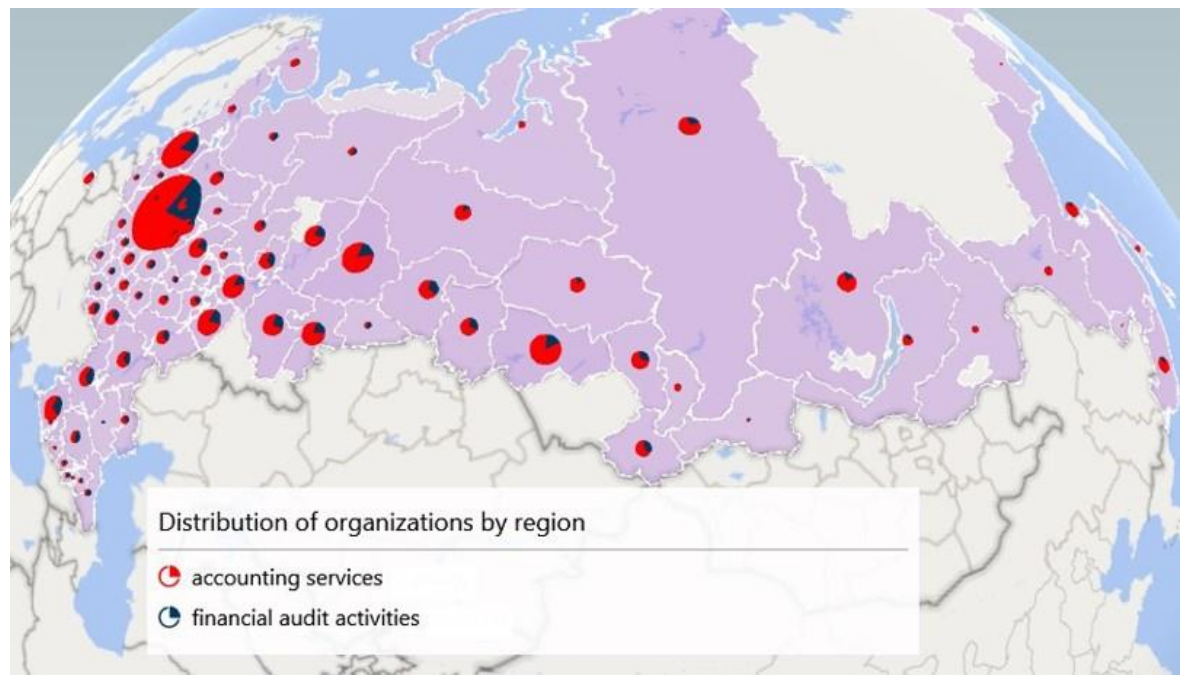

Fig. 2. Distribution of organizations providing accounting services by region of the Russian Federation.

As can be seen from the presented material, the greatest concentration of organizations refers to the city of Moscow and the Moscow region, as well as the city of St. Petersburg and the Leningrad region. This grouping of organizations by region is due to the greatest concentration of both small and large businesses in the central and western federal districts. There is a tendency of growth in the number of outsourcing companies in the Volga Federal 
District due to the reorientation of companies in the central districts to the cheaper price segment. In the East Siberian areas, the number of outsourcing organizations is decreasing.

The distribution of financial activities by types of services provided within the regions is clearly shown in Figure 3

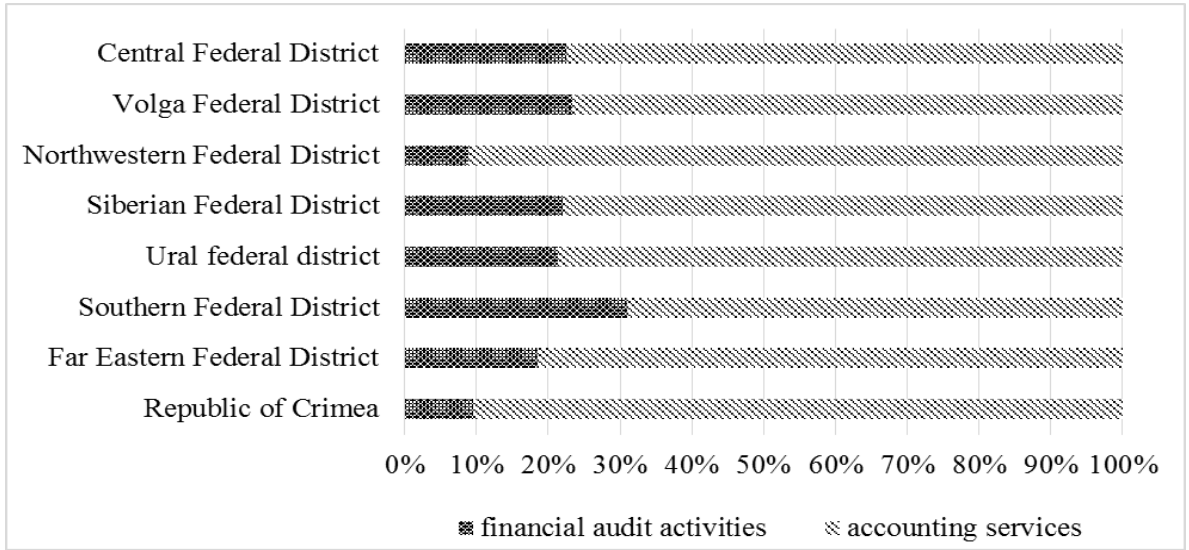

Fig. 3. Distribution of organizations by type of services provided.

The largest share is made up of organizations that provide specialized accounting services in comparison with organizations that provide financial audit services. This ratio is explained by the requirements of the legislation and the market. Since a compulsory audit is carried out in organizations that meet certain criteria, this limits the scope of the provision of audit services. The statistics of an initiative audit indicates that not all organizations order it, and more often the medium and large business segment in connection with its sale or restructuring [12]. According to the Ministry of Finance of the Russian Federation (5), the provision of other services, mainly accounting and legal, in the income structure of audit organizations amounts is about $50 \%$, and the stability of obtaining these incomes is maintained (Table 1).

Table 1 - Revenues of audit organizations by type of activity

\begin{tabular}{|l|l|l|}
\hline & \multicolumn{2}{|l|}{ Russia - total } \\
\cline { 2 - 4 } & $\mathbf{2 0 1 6}$ & $\mathbf{2 0 1 7}$ \\
\hline The share of audit revenues in total revenues for the year,\% & 48.7 & 49.6 \\
\hline $\begin{array}{l}\text { The share of revenue from the provision of non-audit services in the } \\
\text { total revenue for the year,\% }\end{array}$ & 2.7 & 5.1 \\
\hline $\begin{array}{l}\text { The share of income from the provision of other services in total } \\
\text { income for the year,\% }\end{array}$ & 48.6 & 45.3 \\
\hline
\end{tabular}

A critical analysis of the materials on this topic has led to the opinion that the following features are inherent in the modern outsourcing market for accounting services in Russia.

The geography of outsourcing accounting services in Russia shows that it is actively developing, but not evenly, most of the outsourcing companies are concentrated in central districts, in the regions the culture of external accounting services is not popular.

The main customers of accounting services are small businesses, foreign offices and large companies engaged in the optimization of business processes. 
Outsourcing services are most in demand in the trade industry, oil, gas and construction industries, due to large volumes of formalized, repetitive operations that require large time and labor costs for their implementation.

A factor that is holding the development of the accounting outsourcing market is the lack of complete understanding among the customer and the outsourcer of the content of the functional completeness of the accounting service and the criteria for assessing its quality. The ambiguity or ambiguity of the interpretation of the list of services that must be rendered often results in the contractor performing his duties improperly, or rather, not in the way the customer would like. Therefore, a detailed coordination of the subject and object of the service will allow, on the one hand, to fulfill the requirements of the customer, on the other hand, to ensure the proper quality of the service provided.

\section{Discussion}

The real situation in the market for outsourcing accounting functions raises a number of issues that require in-depth study and discussion. In particular, since, in the Russian legislation, there is no formulation of the concept of outsourcing accounting services, this leads to a broad and somewhat contradictory, understanding of the essence of this phenomenon. Therefore, in order to give an objective assessment of the development of accounting outsourcing in Russia, it is necessary to disclose the content of this concept, its forms and types.

Analysis of the definitions of the concept of "outsourcing accounting services" by various authors revealed the following aspects, reflecting the conditions for the functioning of outsourcing accounting services:

- availability of an information infrastructure that ensures the continuous exchange of information, including modern telecommunications, software, and Internet access;

- the presence of the goal of outsourcing: the processes of organization, management, optimization of accounting, preparation of financial statements and its transfer to government bodies;

- availability of a bilateral agreement with an outsourcing company regulating time periods, pricing, content of services and their quality, ways to reduce risks.

Accounting outsourcing as an element of modern methodology for managing economic systems is based on the integration of an organization's information resources with the resources and competencies of outsourcers, accounting service providers in order to achieve a synergistic effect.

Taking into account the considered aspects, from the point of view of theory and practice, gave a more precise definition of the concept of accounting outsourcing Y.S. Lebedinskaya. According to the authors of the article, it looks like this: "Accounting outsourcing is a set of interrelated and interacting actors, namely: outsourcers, customers and regulatory bodies producing a comprehensive outsourcing product, through the integration of intellectual resources and competencies based on the use of information infrastructure, legal framework governing the relations of participants in outsourcing. and provided accounting services [18].

Personal observations of the authors and analysis of the results of the study's allowed us to identify three strategies of companies providing services in the market of accounting outsourcing.

Companies with a small number of staff, low level of outsourcing, providing mainly services for small businesses, limiting their activities in the field of services for the formulation, maintenance and restoration of customer accounting on a one-time and continuous basis. The priority strategy of these companies is to work on retaining customers by improving the quality of services provided and the professional level of staff. 
Companies with a high level of outsourcing offer their clients a wide range of services, not only in accounting, but also related services in tax and financial consulting, business process optimization, and IT support. They serve large and medium businesses, including foreign ones. There are not many such outsourcers on the market due to the limited demand for their services. The ranking of leading Russian companies in the field of accounting function outsourcing, compiled by RAEX (Expert RA) in 2016, included 80 companies in this group, concentrated mainly in large cities and the capital. The top three in 2016 included Intercomp, BDO Unicon, TMF Group.

A special group should be allocated companies for which accounting outsourcing is a related activity in the form of an additional service. These include IT companies and large financial structures of commercial banks that offer their customers, in addition to traditional banking services, accounting, financial planning, in fact, comprehensive outsourcing of financial functions. An example is Sberbank, Promsvyazbank, Tinkoff Bank, Alfa Bank, and other well-known companies. As for IT companies, using the advantages of owning new information technologies, they made a serious competition to traditional outsourcers companies, offering customers, based on available technical capabilities, electronic document management, digital electronic signatures, cloud services, work with mobile applications, integration with banks, government agencies, insurance companies.

For example, the well-known company " $1 \mathrm{C}$ " actively develops accounting outsourcing, providing its customers with a range of accounting services, including cloud accounting, electronic document management with counterparties, a system for checking customer reliability, banking services, access to electronic trading, electronic digital signatures and other. The new direction is successfully developing through a network of regional partners. Possession of technologies and attraction of highly qualified specialists in the field of accounting and taxation provides $1 \mathrm{C}$ high quality and affordable prices for the services offered.

\section{Conclusions}

According to many specialists and experts in the further years, due to the deteriorating economic conditions, an increase in demand in the accounting outsourcing market is not expected, and according to some estimates a decline is predicted. This situation can be changed by the emergence of a new entrant in the outsourcing market - public sector organizations and public corporations. The public sector outsourcing mechanism will reduce budget expenditures, increase the efficiency and quality of public services, focus the executive branch on core activities, ensure the availability of new technologies and management methods, and reduce the number of staff. There are optimistic forecasts regarding the expansion of the accounting outsourcing market, which indicate a trend towards the consolidation of outsourcing companies and the creation of so-called "outsourcing services" in large IT companies, financial structures and banks. This will allow introducing a consolidated approach to the outsourcing processes, making a large-scale transition to electronic document management and robotization of accounting and, as a result, making services better, cheaper and more accessible.

\section{References}

1. Cui, Lan; Liu, Donghui, 3rd International Conference on Judicial, Administrative and Humanitarian Problems of State Structures and Economic Subjects APR 01-04, 252, 336-342 (JAHP. , Domodedovo, RUSSIA, 2018) 
2. http://delivery.acm.org/10.1145/3140000/3133984/p2071-

wahby.pdf?ip $=217.9 .149 .170 \& \mathrm{id}=3133984 \&$ acc $=$ CHORUS\&key $=4 \mathrm{D} 4702 \mathrm{~B} 0 \mathrm{C} 3 \mathrm{E} 38 \mathrm{~B}$

35\%2E4D4702B0C3E38B35\%2E4D4702B0C3E38B35\%2E6D218144511F3437\& a

$\mathrm{cm} \_=1559651915 \_8220 \mathrm{fl}$ ed18ecab092ca4eed184db32d4 (Last accessed 06.03.2019)

3. https://apps.webofknowledge.com/full_record.do?product=WOS\&search_mode=Gener alSearch\&qid $=1 \&$ SID $=$ F5dLBxmrcEnaRzxacaa\&page $=6 \&$ doc $=59$ (Last accessed 07.04.2019)

4. https://www.rusprofile.ru/codes/690000 (Last accessed 17.04.2019)

5. A. E. Ivanov, E. V. Lupshina, Problems and Trends in the Development of Accounting Services Outsourcing in Russia, International Accounting, 5, 9-14 (2014)

6. S. O. Kalendjyan, Outsourcing and delegation of authority in the activities of companies, 272 (Moscow, Delo, 2017)

7. A. S. Kramskikh, I. V. Ovchinnikova, E. V. Ostanina, S. R. Simonyan, Accounting outsourcing in Russia, Bulletin of Kuzbass State Technical University, 1, 146-149 (2015)

8. https://www.minfin.ru/ru/perfomance/audit/audit_stat/MainIndex (Last accessed 27.03.2019)

9. N. V. Palesheva, Requirements for an outsourcing contract for accounting services from the standpoint of reducing the risk of economic activity, Economics and Management: problems, solutions, 4(8), 122-129 (2017)

10. Russell, Jesse Accounting Outsourcing, Jesse Russell, 167 (Moscow, VSD, 2013)

11. https://raexpert.ru/ratings/outsourcing/2016 (Last accessed 22.04.2019)

12. http://www.gks.ru/free_doc/doc_2018/rusfig/rus18.pdf (Last accessed 22.02.2019)

13. I. L. Rudaya, Outsourcing: methodology and practice: Monograph, 230 (Samara: Publishing house "Univers-group", 2009)

14. https: //www.business.ru/article/731-samye-vostrebovannye-uslugi-v-2019-godu (Last accessed 12.03.2019)

15. I. V. Tikhonova, Accounting outsourcing is one of the forms of organization of accounting // Current status and prospects for the development of accounting, economic analysis and audit: materials of the International Scientific and Practical Conference, 265-268 (Irkutsk: Baikal State University, 2015)

16. J. Brian, Haywood, Outsourcing: In search of competitive advantages: Trans. from English, 174 (Moscow, Williams, 2004)

17. Y. S. Lebedinskaya, A. S. Konshin, "Accounting Outsourcing: Concept and Specific Features", Vector of Science at TSU. Series: Economics and Management, 1(24), 49-54 (2016) 